\title{
The role of focal adhesion kinase in transforming growth factor- $\beta 2$ induced migration of human lens epithelial cells
}

\author{
JIE LIU ${ }^{1,2}$, DAN XU ${ }^{3}$, JINGMING LI $^{1}$, NING GAO ${ }^{1}$, CHONGBING LIAO $^{4}$, RUIHUA JING $^{1}$, \\ BOGANG WU $^{5}$, BO MA ${ }^{1}$, YONGPING SHAO ${ }^{3,4}$ and CHENG PEI ${ }^{1}$
}

\begin{abstract}
${ }^{1}$ Department of Ophthalmology, First Affiliated Hospital of Medical School of Xi'an Jiaotong University, Xi'an, Shaanxi 710061, P.R. China; ${ }^{2}$ Department of Biochemistry, University of Texas Health Science Center at San Antonio, San Antonio, TX 78229, USA; ${ }^{3}$ Key Laboratory of Biomedical Information Engineering of the Ministry of Education,

Department of Biological Science and Engineering, School of Life Science and Technology;

${ }^{4}$ Center for Translational Medicine, Frontier Institute of Science and Technology, Xi'an Jiaotong University, Xi'an, Shaanxi 710049, P.R. China; ${ }^{5}$ Department of Molecular Medicine, University of Texas Health Science Center at San Antonio, San Antonio, TX 78229, USA
\end{abstract}

Received May 24, 2018; Accepted September 19, 2018

DOI: $10.3892 /$ ijmm.2018.3912

\begin{abstract}
The migration of lens epithelial cells towards the posterior capsule is a key event in the development of posterior capsule opacification (PCO). Accumulating evidence has described crosstalk between growth factors and adhesive signaling pathways in wound healing and cell migration. The aim of the present study was to elucidate an aberrant transforming growth factor (TGF)- $\beta 2$ signaling pathway that regulated the migration of lens epithelial cells in the pathological context of PCO. The expression of fibronectin, focal adhesion kinase (FAK) and phosphorylated (p)-FAK in HLE-B3 cells following TGF- $\beta 2$ treatment was determined by western blot analysis and the expression of integrin $\alpha 5 \beta 1$ was detected by flow cytometry. Cell migration capacity was measured by wound healing and Transwell assays in the presence of 1,2,4,5-tetraaminobenzene tetrahydrochloride, a selective FAK inhibitor, fibronectin small interfering RNA interference, arginylglycylaspartic acid peptides or
\end{abstract}

Correspondence to: Dr Cheng Pei, Department of Ophthalmology, First Affiliated Hospital of Medical School of Xi'an Jiaotong University, 277 Yanta West Road, Xi'an, Shaanxi 710061, P.R. China E-mail: peich71@163.com

Dr Yongping Shao, Center for Translational Medicine, Frontier Institute of Science and Technology, Xi'an Jiaotong University, 28 Xianning West Road, Xi'an, Shaanxi 710049, P.R. China

E-mail: yongping.shao@mail.xjtu.edu.cn

Abbreviations: HLE-B3, human lens epithelial cells; FN, fibronectin; FAK, focal adhesion kinase; PCO, posterior capsule opacification; TGF- $\beta$, transforming growth factor- $\beta$; RGD, arginylglycylaspartic acid; EMT, epithelial-to-mesenchymal transition

Key words: transforming growth factor- $\beta 2$, migration, integrin-focal adhesion kinase signaling $\alpha 5 \beta 1$-integrin neutralizing antibodies. The 1,2,4,5-tetraaminobenzene tetrahydrochloride was administered daily to 16 rabbits following cataract surgery. Fibronectin and TGF- $\beta$ expression were increased in the PCO group, demonstrated by immunofluorescence assays. PCO grading was conducted by slit-lamp biomicroscopy and evaluation of posterior capsule opacification software. It was observed that TGF- $\beta 2$ promoted HLE-B3 cell migration and upregulated fibronectin expression, which was followed by an increased phosphorylation of FAK. In addition, TGF- $\beta 2$ treatment and fibronectin surface coating significantly increased cell migration and FAK activation, which was inhibited by disrupting fibronectin-integrin $\alpha 5 \beta 1$ interaction with the arginylglycylaspartic acid peptide, $\alpha 5 \beta 1$-integrin neutralizing antibody or fibronectin depletion. Finally, suppression of FAK signaling by its inhibitor significantly decreased cell migration in vitro and attenuated PCO development in vivo. In summary, TGF- $\beta 2$ was indicated to promote the migration of lens epithelial cells through the TGF- $\beta 2 /$ fibronectin/integrin/FAK axis. Inhibition of FAK activity decreased TGF- $\beta 2$-mediated cell migration in vitro and improved the symptoms of PCO in a rabbit model.

\section{Introduction}

Cataracts affect millions of patients worldwide, a significant proportion of whom achieve good visual restoration through surgical intervention. However, remnant lens epithelial cells (LECs) may proliferate, transdifferentiate and undergo a wound healing response driven by continuous pathological factors caused by surgery, including cascade reactions. The residual LECs migrate towards the posterior capsule, proliferate abnormally and secrete extracellular matrix (ECM), causing obscuration of the central visual axis and a secondary loss of vision, referred to as posterior capsule opacification (PCO) $(1,2)$. A thorough mechanistic understanding of PCO is crucial for the prevention and identification of effective treatment options for this condition. 
A variety of structural and signaling proteins have been demonstrated to facilitate PCO development: Transforming growth factor (TGF)- $\beta$ expression is increased in response to injury (3) and it has been demonstrated that TGF- $\beta$ not only induces epithelial-to-mesenchymal transition (EMT) in LECs, but also regulates cell migration, which are each considered key events in the initiation of PCO (4). In addition to the canonical Mothers against decapentaplegic signaling pathway, which mediates essential functions of TGF- $\beta$, non-canonical signaling pathways also exist and are involved in cell type- or process-specific events (5). Accumulating evidence indicates the presence of crosstalk between growth factors and adhesive signaling pathways. Firstly, TGF- $\beta$ may regulate integrin signaling through physical interaction between TGF- $\beta$ receptors (TGF- $\beta$ R) and integrins (6), stable interactions between the Type II TGF- $\beta$ receptor (T $\beta$ RII) and $\alpha 5 \beta 1$ integrin have also been described in rapid fibrillogenesis (7), and the association of integrin $\alpha v \beta 3$ with TGF- $\beta$ R has been suggested to enhance TGF- $\beta$-induced invasion of breast cancer cells and contribute to abnormal wound healing in lung fibroblasts $(8,9)$. Secondly, TGF- $\beta$ may upregulate integrin expression: TGF- $\beta$ signaling increased $\alpha 5 \beta 1$ integrin expression in keratinocytes during wound healing and promoted carcinoma cell migration (10). Finally, TGF- $\beta$ may indirectly regulate the integrin signaling pathway by modulating the ECM: TGF- $\beta$ signaling exerts critical effects on the expression of genes encoding ECM components (6). In response to TGF- $\beta$ stimulation, fibronectin is produced and assembled into fibers that are connected with the terminal portion of $\alpha$-smooth muscle actin-positive stress fibers through focal adhesion (11). TGF- $\beta 1$-induced phosphorylation of focal adhesion kinase (FAK) only occurs when cells adhere to fibronectin secreted by TGF- $\beta$-stimulated cells (12). Following cataract surgery, increased levels of active TGF $\beta 2$ are present in the aqueous humor $(13,14)$ and induce aberrant expression of ECM proteins, including fibronectin (15). While it has been hypothesized that the microenvironment in certain disease states may alter integrin function and facilitate PCO development (16), the underlying mechanism remains unknown.

FAK serves a key role in normal cell migration and is implicated in the metastasis of a wide variety of human cancer cells, including hepatocellular carcinoma cells (17), GS-Tg microglia (18), glioblastoma cells (19) and breast cancer cells (20). Upon extracellular stimuli, FAK is activated by phosphorylation and initiates a signaling cascade that promotes cell migration (21). Previous studies have demonstrated that FAK is required for TGF- $\beta$-induced EMT in hepatocytes and lung fibroblasts $(12,22)$. The downregulation of FAK abrogates platelet-derived growth factor-BB-stimulated cell migration and cell motility toward fibronectin and collagen (23). However, at present, the role of FAK in TGF- $\beta 2$-induced human LEC migration in PCO has not been investigated.

Integrin signaling mediates important functions of TGF- $\beta$, including cell adhesion and migration (24). The aim of the present study was to investigate the crosstalk between integrins and TGF- $\beta 2$ signaling, and the role of FAK in the context of $\mathrm{PCO}$, in order to determine whether TGF- $\beta 2$ interacts with integrin/FAK by regulating fibronectin expression, and whether inhibition of FAK activity decreases TGF- $\beta 2$-enhanced cell migration in vitro. The efficacy of FAK inhibition in improving the symptoms of PCO was also investigated in a rabbit model. The present results demonstrate that TGF- $\beta 2$ promotes the migration of lens epithelial cells through the TGF- $\beta 2 /$ fibronectin/integrin/FAK axis and inhibition of FAK activity decreases TGF- $\beta 2$-mediate cell migration; thus improving the symptoms of PCO in a rabbit model.

\section{Materials and methods}

Cell culture and reagents. HLE-B3 cells were obtained from American Type Culture Collection (ATCC; Manassas, VA, USA) and cultured in Eagle's Minimum Essential Medium (EMEM; ATCC) supplemented with $20 \%$ fetal bovine serum (Gibco; Thermo Fisher Scientific, Inc., Waltham, MA, USA) and $1 \%$ penicillin-streptomycin. The cells were cultured at $37^{\circ} \mathrm{C}$ in a humidified atmosphere containing $5 \% \mathrm{CO}_{2}$, and the culture medium was changed every 2 days. Cells were used between passages 2 and 8 for all experiments. Recombinant human TGF- $\beta 2$ was purchased from PeproTech, Inc. (Rocky Hill, NJ, USA) and FAK inhibitor-1,2,4,5-tetraaminobenzene tetra hydrochloride which prevents FAK autophosphorylation at Tyr397, was obtained from Santa Cruz Biotechnology, Inc. (Dallas, TX, USA). The $\alpha 5 \beta 1$-integrin neutralizing antibody was purchased from EMD Millipore (Billerica, MA, USA).

Cell treatment. HLE-B3 cells were treated with different doses $(0,0.1,0.5,1,5$ and $10 \mathrm{ng} / \mathrm{ml})$ of TGF- $\beta 2$ for $48 \mathrm{~h}$ at $37^{\circ} \mathrm{C}$, or for various times $(0,24,48,72 \mathrm{~h})$ at a concentration of $10 \mathrm{ng} / \mathrm{ml}$. HLE-B3 cells were otherwise seeded on fibronectin- (Advanced Biomatrix, Inc., San Diego, CA, USA; cat. no. 0505; 1:10), collagen- (Advanced Biomatrix, Inc.; cat. no. 5007; 1:30) or polylysine-coated surfaces (Sigma-Aldrich; Merck KGaA, Darmstadt, Germany; cat. no. P4707, 1:10) for $1 \mathrm{~h}$ at $37^{\circ} \mathrm{C}$; and were then treated with 1,2,4,5-tetraaminobenzene tetrahydrochloride $(1 \mu \mathrm{M}, 2 \mu \mathrm{M})$ for $12 \mathrm{~h}$ at $37^{\circ} \mathrm{C}$ prior to TGF- $\beta 2$ (10 $\mathrm{ng} / \mathrm{ml})$ for an additional $48 \mathrm{~h}$.

Western blot analysis. Following treatment, cell culture medium was removed, the HLE-B3 cells were washed and whole-cell lysates were harvested by $1 \mathrm{X}$ loading buffer (diluted from 2X Laemmli sample buffer; Bio-Rad Laboratories, Inc., Hercules, CA, USA). Bicinchoninic acid assay was used to quantify the protein concentration and $20 \mu \mathrm{g}$ per lane was loaded to $8 \%$ SDS-PAGE gels and then electrotransferred onto polyvinylidene fluoride membranes. The membranes were blocked with $5 \%$ bovine serum albumin (BSA; Thermo Fisher Scientific, Inc.) for $1 \mathrm{~h}$ at room temperature, and then incubated with primary antibodies overnight at $4^{\circ} \mathrm{C}$. Primary antibodies against fibronectin (Santa Cruz Biotechnology, Inc.; cat. no. Sc-9068), phosphorylated FAK (Cell Signaling Technology, Inc., Danvers, MA, USA; cat. no. 3283s), FAK (Cell Signaling Technology, Inc.; cat. no. 13009) and $\beta$-actin (Sigma-Aldrich; Merck KGaA; cat. no. A2066) were diluted in TBS with $0.1 \%$ Tween-20 (TBST) at a dilution of 1:1,000. Following washing, the membranes were incubated with a horseradish peroxidase-conjugated secondary antibody (Sigma-Aldrich; Merck KGaA; cat. no. AP156P; 1:1,000) at room temperature for $1 \mathrm{~h}$. The results of the western blot analysis were visualized using enhanced chemiluminescence substrate solution (Genshare Biological, Shaanxi, China) and the protein expression levels were measured using 
densitometry with ImageJ 1.50i software (National Institutes of Health, Bethesda, MD, USA).

Flow cytometry analysis. The HLE-B3 cells were collected from the culture following treatment with TGF- $\beta 2(10 \mathrm{ng} / \mathrm{ml})$ for different time intervals $(0,24,48$ and $72 \mathrm{~h})$, resuspended at a concentration of $4 \times 10^{6}$ cells $/ \mathrm{ml}$ in complete medium and washed three times with washing buffer (PBS containing $2 \% \mathrm{BSA}$ and $0.05 \% \mathrm{NaN}_{3}$ ). Subsequently, the cells were blocked in $100 \mu \mathrm{l}$ blocking buffer [1X PBS with $2 \%$ fetal bovine serum and 1:10,000 IgG (Thermo Fisher Scientific, Inc.; cat. no. NB410280885)] for $15 \mathrm{~min}$. The $\alpha 5 \beta 1$-integrin neutralizing primary antibody (cat. no. MAB 1969; 1:100) was added and incubated on ice $\left(4^{\circ} \mathrm{C}\right)$ for $1 \mathrm{~h}$. Subsequent to washing twice, the cells were resuspended with an Alexa Fluor-conjugated goat anti-mouse secondary antibody (Thermo Fisher Scientific, Inc.; cat. no. A28175; 1:400) for $30 \mathrm{~min}$ on ice. The cells were washed twice with PBS and fixed at room temperature in $500 \mu 14 \%$ formaldehyde for $30 \mathrm{~min}$ prior to analysis via flow cytometry on a CytoFLEX system (Beckman Coulter, Inc., Brea, CA, USA).

Wound healing assay. Cell culture dishes were coated with fibronectin $(50 \mu \mathrm{g} / \mathrm{ml})$ at $4^{\circ} \mathrm{C}$ overnight. To create a cell-free gap, the Ibidi Culture-Insert from Ibidi GmbH (Martinsried, Germany) was used according to the manufacturer's protocol, as the regular scratch method was hypothesized to disrupt the fibronectin on the dish surface. HLE-B3 cells were incubated with arginylglycylaspartic acid (RGD) peptide $(50 \mu \mathrm{g} / \mathrm{ml})$ or the aforementioned $\alpha 5 \beta 1$-integrin neutralizing antibody (1:100) for $1 \mathrm{~h}$. An HLE-B3 cell suspension $(70 \mu \mathrm{l})$ at $3 \times 10^{5}$ cells $/ \mathrm{ml}$ was seeded in the designated areas and then cultured at $37^{\circ} \mathrm{C}$ for $24 \mathrm{~h}$ to form a confluent layer. Following gentle removal of the Culture-Insert Well, non-adherent cells were washed away by PBS and cell-free medium $(2 \mathrm{ml})$ was added. The cells were incubated at $37^{\circ} \mathrm{C}$ for an additional $24 \mathrm{~h}$ and images were captured at the indicated times $(0,6,12$ and $24 \mathrm{~h})$. The wound area was analyzed using ImageJ $1.50 \mathrm{i}$ software.

Small interfering RNA (siRNA) knockdown and cell migration assay. Fibronectin siRNAs were obtained from Shanghai GenePharma Co., Ltd. (Shanghai, China). Briefly, $1.5 \times 10^{5}$ HLE-B3 cells were seeded into 6 -well plates, and transfected $24 \mathrm{~h}$ later with $1.25 \mu \mathrm{l}$ fibronectin siRNAs (Sangon Biotech Co., Ltd., Shanghjai, China; $20 \mu \mathrm{m}$ ) for $48 \mathrm{~h}$ using RNAiMAX transfection reagents (Thermo Fisher Scientific, Inc.) according to the manufacturer's protocol. The sequence of fibronectin siRNA was 5'-GCACAA CUUCGAAUUAUGATT-3', and that of the non-specific scrambled siRNA (niR16) of a similar length was 5'-AAU AUUGGCGUUAAGAUUCUA-3'. Following siRNA transfection, HLE-B3 cells were exposed to TGF- $\beta 2(10 \mathrm{ng} / \mathrm{ml})$ for $48 \mathrm{~h}$ prior to seeding onto Costar Transwell permeable chambers (Corning Incorporated, Corning, NY, USA) with an $8.0 \mu \mathrm{m}$ polycarbonate membrane pore size in 24-well plates. Complete EMEM (1 ml) was placed in the basolateral chamber, and $200 \mu \mathrm{l}$ cell resuspension in serum-free medium was placed in the upper chamber. Cells were incubated at $37^{\circ} \mathrm{C}$ for an additional $24 \mathrm{~h}$ and fixed at room temperature with $4 \%$ paraformaldehyde for $10 \mathrm{~min}$. The cells were subsequently stained with $0.5 \%$ crystal violet solution for $5 \mathrm{~min}$ at room temperature and then washed with PBS 3 times. Light microscopy images were captured at a magnification of $\mathrm{x} 20$. The total number of cells that had migrated to the lower side of the membrane was quantified.

In vivo animal cataract surgery model. A total of 16 male Chinese white rabbits (provided by Animal Experimentation Center Affiliated to the Medical School of Xi'an Jiaotong University, Xi'an, China; maintained at $25^{\circ} \mathrm{C}$ with $0.04 \%$ $\mathrm{CO}_{2}$ and food and water provided ad libitum), aged 3 months and weighing $2.0 \pm 0.2 \mathrm{~kg}$, were used in the present study. All animal experiments complied with the ARRIVE guidelines (25) and the 2013 AVMA Guidelines for the Euthanasia of Animals (26) and were approved by the Animal Experimentation Center Affiliated to the Medical School of Xi'an Jiaotong University. Pre-examination was conducted on the rabbits under a slit lamp to ensure that they were eye disease-free. Phacoemulsification and surgery were performed on the right eye of each rabbit by the same senior surgeon who was blinded to the treatment groups. The animals in the control $(n=8)$ and experimental groups $(n=8)$ were administered topical steroid drops containing $3.5 \%$ lidocaine hydrochloride ophthalmic solution (Akorn, Inc., Lake Forest, IL, USA) to control postoperative inflammation and daily subconjunctival injection of abstractum: Epinephrine and cyclopentolate hydrochloride (Tianjin Jinyao Amino Acid Co., Ltd., Tianjin, China; 1:1) to maintain pupil dilation. As there was a high circulation rate in the aqueous humor and, therefore, the drug was rapidly diluted by intraocular injection. Daily drug delivery was performed by subconjunctival injection of $10 \mu \mathrm{l}$ dimethyl sulfoxide (DMSO) in the control group and $10 \mu 1$ 1,2,4,5-tetraaminobenzene tetrahydrochloride $(10 \mu \mathrm{M})$ in the treatment group for 60 days. Anterior chamber inflammatory reaction grading was conducted as previously described (27). PCO development grading was performed by slit lamp microscopy (clinical scoring was based on the combination of the area and severity of the opacity (28) and evaluation via EPCO2000 posterior capsule opacification software (http://www.epco2000.de/) (27). Images were captured using retroillumination. All the PCO images were graded by an experienced ophthalmologist twice, with an interval of 1 week. The rabbits were euthanized on the 60th day.

Surgical procedures. All surgical procedures were performed under general anesthesia by injecting sodium pentobarbital (30 $\mathrm{mg} / \mathrm{kg}$ intravenously) from the ear base and topical anesthesia by administering 3.5\% lidocaine hydrochloride ophthalmic solution to the eye surface. Pupil dilation was achieved by application of $1 \%$ cyclopentolate hydrochloride $30 \mathrm{~min}$ prior to surgery, and the eyelids were retracted with a wire lid speculum. A $3.0 \mathrm{~mm}$ blade was used to make a small corneal incision, and sodium hyaluronate was injected into the anterior chamber to fill the opening and protect the corneal endothelium. Continuous curvilinear capsulorhexis was then performed, and cortical materials and the nuclei were removed by phacoemulsification. Repeated irrigation and aspiration were performed to remove all cortical materials, which was followed by implantation of an intraocular lens (Oculens; Rafi Systems Inc., Diamond Bar, CA, USA) in the capsular bag. 
A

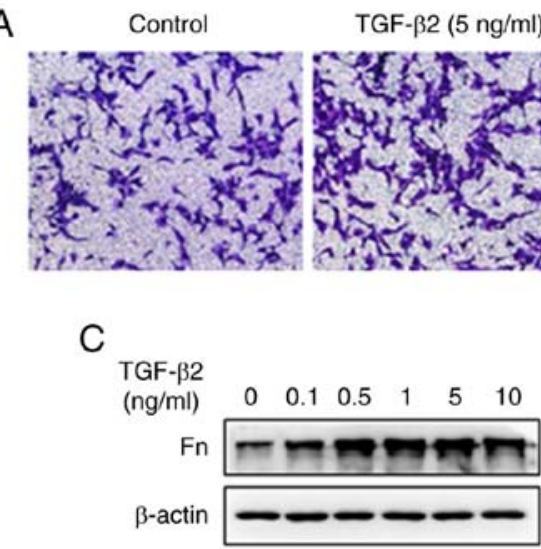

E

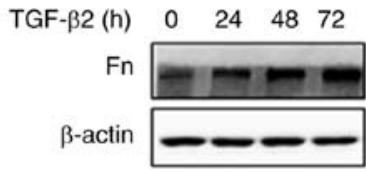

TGF- $\beta 2(10 \mathrm{ng} / \mathrm{ml})$

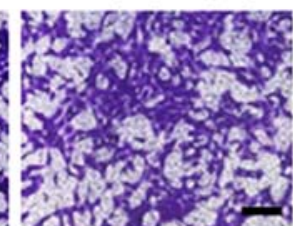

B

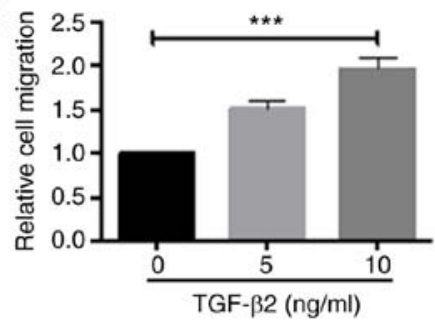

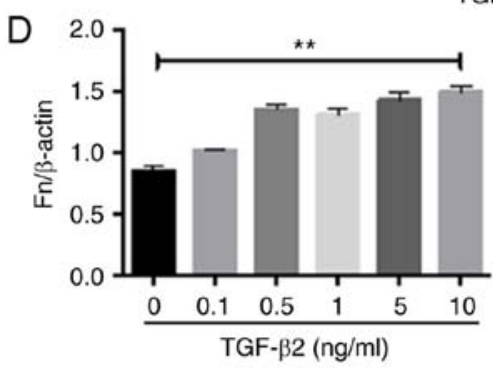

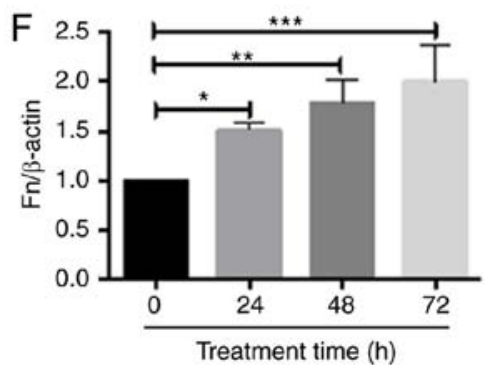

Figure 1. TGF- $\beta 2$ promotes the migration of lens epithelial cells and increases Fn expression. (A) HLE-B3 cells were treated with TGF- $\beta 2$ ( 0,5 and 10 ng/ml) for $48 \mathrm{~h}$ prior to Transwell assay. Staining with crystal violet solution was used to visualize cells. Scale bar=100 $\mu \mathrm{m}$. (B) TGF- $\beta 2$ promoted cell migration in a dose-dependent manner. (C) HLE-B3 cells were treated with TGF- $\beta 2$ at the indicated concentrations for $48 \mathrm{~h}$ and examined by western blot analysis. (D) Quantification of the western blot analysis results. (E) HLE-B3 cells were treated with TGF- $\beta 2$ (10 ng/ml) for $0,24,48$ and $72 \mathrm{~h}$, and examined by western blot analysis. (F) Quantification of the western blot analysis results. A one-way analysis of variance followed by a Least Significant Difference post-hoc-test was used to compare mean differences from multiple groups. Data from three independent experiments are presented as means \pm standard error of the mean. ${ }^{*} \mathrm{P}<0.05,{ }^{* *} \mathrm{P}<0.01$ and ${ }^{* * *} \mathrm{P}<0.001$. TGF- $\beta 2$, transforming growth factor- $\beta 2$; HLE, human lens epithelial cells; Fn, fibronectin.

Immunofluorescence. The lens capsule was dissected from the post-operative rabbits and then fixed at room temperature for $2 \mathrm{~h}$ in $4 \%$ paraformaldehyde. Lens were then incubated in $20 \%$ sucrose overnight at $4^{\circ} \mathrm{C}$ and frozen in Optimal Cutting Temperature compound (Thermo Fisher Scientific, Inc.). Cryosections $(10 \mu \mathrm{m})$ were then produced for an immunofluorescence assay. For this assay, sections were blocked at room temperature for $1 \mathrm{~h}$ using blocking solution (2\% goat serum, $1 \%$ BSA and $0.25 \%$ Triton X-100). Primary antibodies including anti-fibronectin antibody (Sigma-Aldrich; Merck KGaA; cat. no. F0791) and anti-TGF- $\beta$ antibody (Abcam, Cambridge, UK; cat. no. ab113670) were used, and fluorescein isothiocyanate-conjugated goat anti-mouse antibody (Jackson ImmunoResearch Laboratories, Inc., West Grove, PA, USA; cat. no. 115096146; 1:500) and Alexa Fluor ${ }^{\circledR}$ 647-conjugated goat anti-rabbit antibody (Jackson ImmunoResearch. Inc. PA, USA; cat. no. 111606003, 1:500) for were applied as secondary antibodies for fibronextin and TGF- $\beta$, respectively. Sections were then mounted with Vectasheild mounting media with DAPI and examined using a Zeiss confocal microscope (Zeiss AG, Oberkochen, Germany) at a magnification of x10.

Statistical analysis. The data are presented as the mean \pm standard error of the mean of at least three repeats. A one-way analysis of variance followed by Least Significant Difference post-hoc-test was used to compare mean difference among multiple groups. The mean differences from two groups were analyzed by a paired Student's t-test. All statistical analyses were conducted using GraphPad Prism 6.0c software (GraphPad Software, Inc., La Jolla, CA, USA). P<0.05 was considered to indicate a statistically significant difference.

\section{Results}

TGF- $\beta 2$ promotes the migration of LECs and enhances fibronectin expression. Migration of LECs to the posterior pole of the lens capsule is an essential step during the development of PCO (29). TGF- $\beta 2$ has been demonstrated to be a pro-migratory factor for a number of cell types (30). TGF- $\beta 2$ has also been used to treat human lens epithelial cells to promote epithelial-mesenchymal transition and PCO progression (31). In the present study, HLE-B3 cells were treated with different doses $(0,5$ and $10 \mathrm{ng} / \mathrm{ml})$ of TGF- $\beta 2$ for $48 \mathrm{~h}$ and cell migration was analyzed with the Transwell assay. TGF- $\beta 2$ was demonstrated to promote HLE-B3 cell migration in a dose-dependent manner (Fig. 1A and B). The expression of fibronectin, an ECM component implicated in cell migration, was also analyzed by western blot analysis. TGF- $\beta 2$ induced fibronectin expression dose- and time-dependently (Fig. 1C-F). Therefore, TGF- $\beta 2$ increased the migration capacity of HLE-B3 cells and induced the expression of fibronectin. 
A
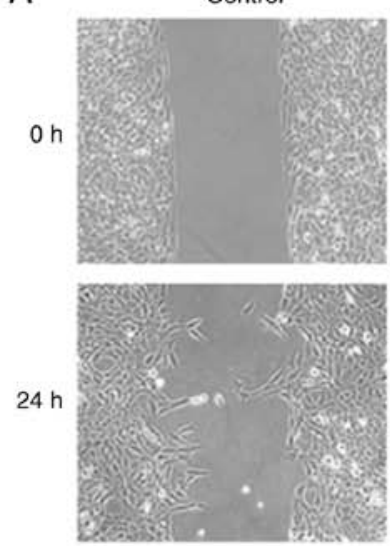

B

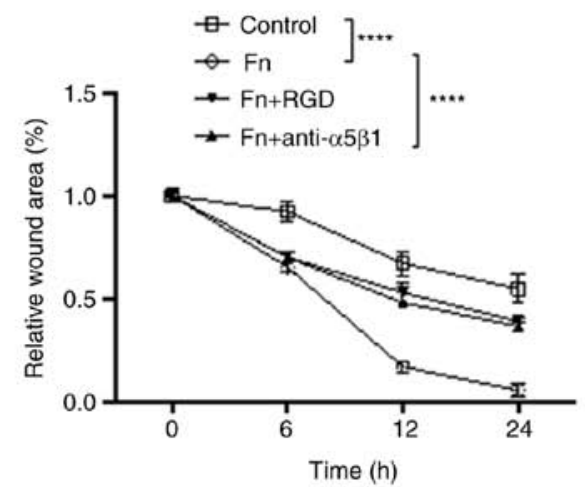

$\mathrm{Fn}+\mathrm{RGD}$
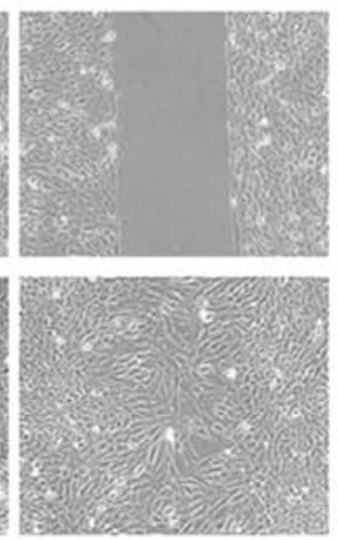
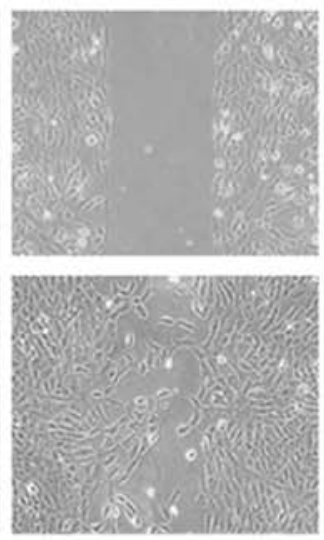

Fn+anti- $\alpha 5 \beta 1$
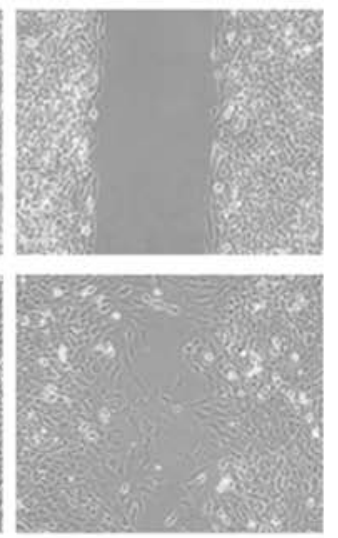

D SiRNA

Ctrl
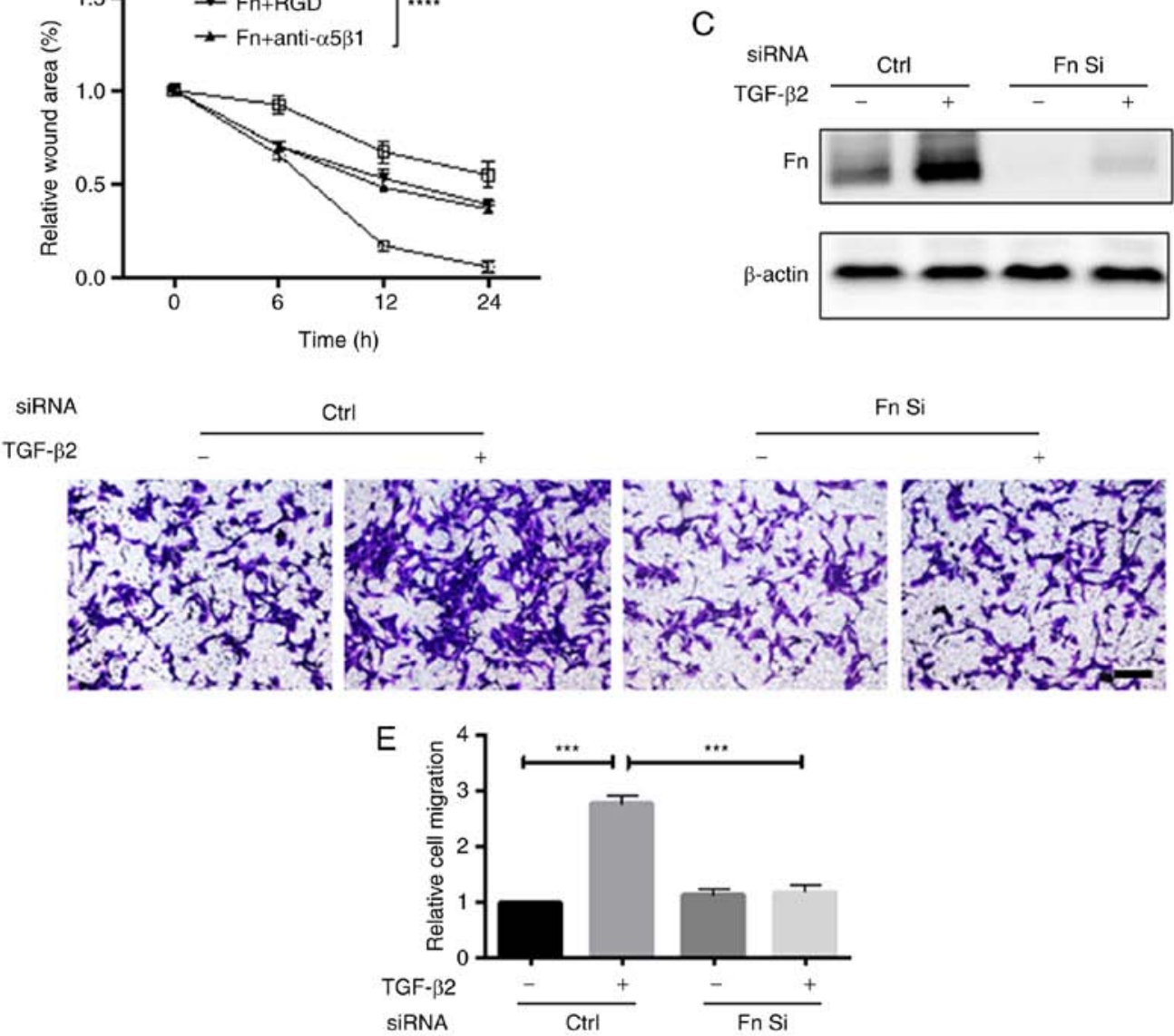

Figure 2. Fn is required for the pro-migration effect of TGF- $\beta 2$ on HLE-B3 cells. HLE-B3 cells were pre-treated with RGD peptide (50 $\mu \mathrm{g} / \mathrm{ml})$ or $\alpha 5 \beta 1$-integrin blocking antibody (1:100) for $1 \mathrm{~h}$ prior to seeding on the culture surface coated with Fn (50 $\mu \mathrm{g} / \mathrm{ml})$ for $24 \mathrm{~h}$, allowing cell attachment and recovery. Images were captured at the indicated time points. (A) Wound healing at 0 and $24 \mathrm{~h}$. The wound area was measured and analyzed with ImageJ software. (B) The relative wound area (remaining wound area/total) is presented in the line graph. A larger wound ratio indicated slower wound closure and there was a significant difference at $24 \mathrm{~h}$. (C) HLE-B3 cells were cultured to $30 \%$ confluence and then continuously exposed to control siRNA or Fn siRNA for $48 \mathrm{~h}$ prior to treatment with $10 \mathrm{ng} / \mathrm{ml}$ TGF- $\beta 2$ for an additional $48 \mathrm{~h}$. The cells were the collected to perform (C) western blot analysis or (D) Transwell assay for $24 \mathrm{~h}$. Scale bar=100 $\mu \mathrm{m}$. (E) Quantification of the Transwell assay results. A one-way analysis of variance followed by a Least Significant Difference post-hoc-test was used to assess mean differences from multiple groups. Data from three independent experiments are presented as means \pm standard error of the mean. ${ }^{*} \mathrm{P}<0.05$; ${ }^{* *} \mathrm{P}<0.01,{ }^{* * * *} \mathrm{P}<0.001$ and ${ }^{* * * *} \mathrm{P}<0.0001$. TGF- $\beta 2$, transforming growth factor- $\beta 2 ;$ HLE, human lens epithelial cells; Fn, fibronectin; RGD, arginylglycylaspartic acid; siRNA, small interfering RNA; ctrl, control.

Fibronectin is required for the pro-migration effect of TGF- $\beta 2$ on HLE-B3 cells. TGF- $\beta 2$-enhanced migration of HLE-B3 cells is associated with upregulated fibronectin expression (32). Therefore, the present study aimed to investigate whether fibronectin mediated the pro-migration function of TGF- $\beta 2$.
The role of fibronectin in cell migration was first examined by wound healing assay. The rate of wound closure was significantly increased in the presence of fibronectin (Fig. 2A and B). Additionally, disruption of the binding of fibronectin to its receptor, $\alpha 5 \beta 1$-integrin, with the RGD peptide or $\alpha 5 \beta 1$-integrin 


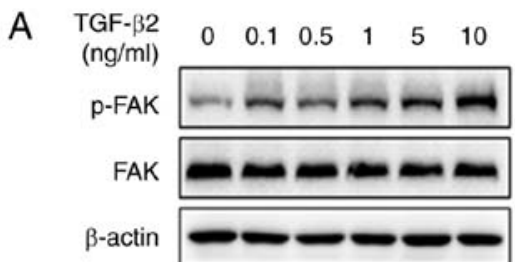

B

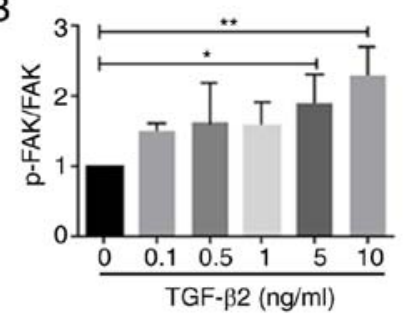

C

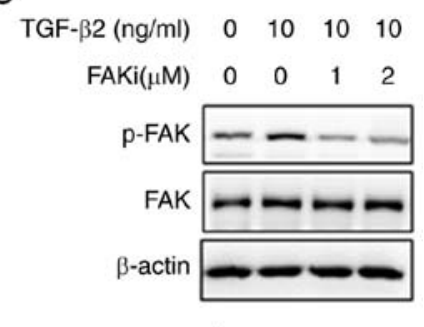

$2 \mu \mathrm{M}$

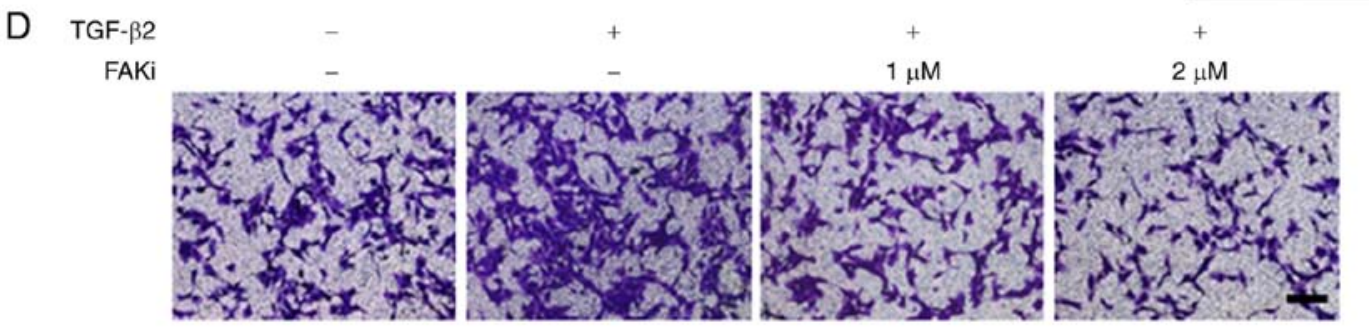

$\mathrm{E}$

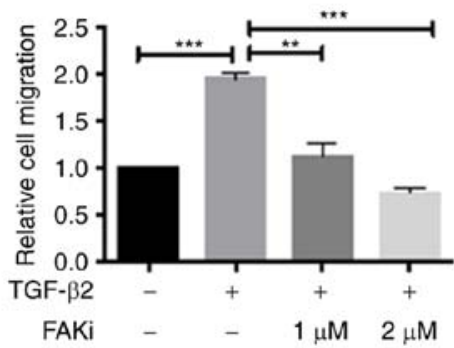

$\mathrm{F}$

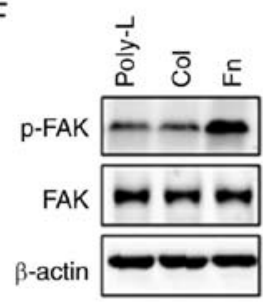

G

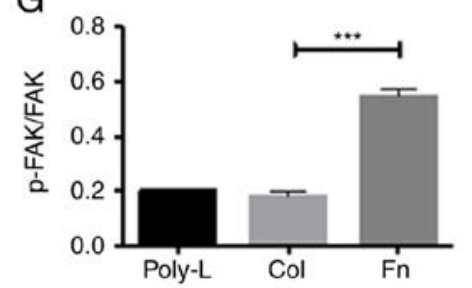

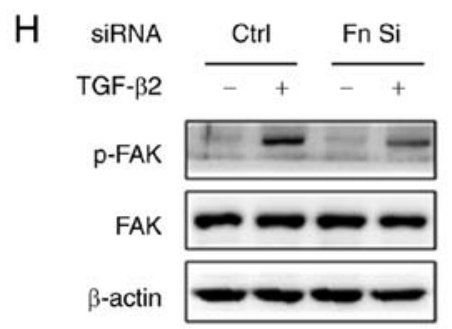

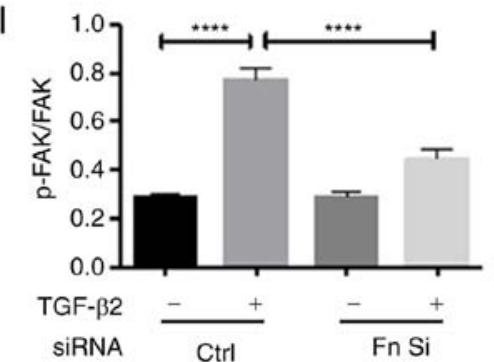

Figure 3. FAK is the downstream effector of the TGF- $\beta 2 / F n$ axis. (A) HLE-B3 cells were treated with TGF- $\beta 2$ at the indicated concentrations for $48 \mathrm{~h}$, and examined using western blot analysis. (B) Quantification of the western blot analysis results. The HLE-B3 cells were then treated with 1,2,4,5-tetraaminobenzene tetrahydrochloride for $12 \mathrm{~h}$ prior to TGF- $\beta 2(10 \mathrm{ng} / \mathrm{ml})$ for an additional $48 \mathrm{~h}$, and then examined by (C) western blot analysis and (D) Transwell assays. Scale bar $=100 \mu \mathrm{m}$. (E) Quantification of the Transwell assay results. (F) The HLE-B3 cells were seeded on culture surfaces coated with Fn (50 $\mu \mathrm{g} / \mathrm{ml})$, Poly-L or $\mathrm{Col}(50 \mu \mathrm{g} / \mathrm{ml})$ for $1 \mathrm{~h}$ and then collected for western blot analysis to investigate the levels of p-FAK. (G) Quantification of the western blot analysis results. (H) Western blot analysis indicated that knockdown of Fn by siRNA decreased the activation of FAK by TGF- $\beta 2$. (I) Quantification of the western blot analysis results. A one-way analysis of variance followed by a Least Significant Difference post-hoc test was used to assess mean differences from multiple groups. Data from three independent experiments are presented as means \pm standard error of the mean. ${ }^{*} \mathrm{P}<0.05,{ }^{* * *} \mathrm{P}<0.01,{ }^{* * * *} \mathrm{P}<0.001$ and ${ }^{* * * * *} \mathrm{P}<0.0001$. FAK, focal adhesion kinase; TGF- $\beta 2$, transforming growth factor- $\beta 2$; HLE, human lens epithelial cells; $p$, phosphorylated; Fn, fibronectin; FAKi, FAK inhibitor; Col, collagen; Poly-L, polylysine; siRNA, small interfering RNA.

neutralizing antibody, inhibited the migration-promoting effect of fibronectin, indicating that fibronectin serves an important role in the migration of HLE-B3 cells. It was then determined whether TGF- $\beta 2$-induced cell migration is dependent on the upregulation of fibronectin. siRNA was used to knock down fibronectin expression in HLE-B3 cells. As demonstrated in Fig. $2 \mathrm{C}$, siRNA effectively depleted basal and TGF- $\beta 2$-induced expression of fibronectin. Notably, fibronectin knockdown almost completely inhibited TGF- $\beta 2$-induced cell migration (Fig. 2D and E), confirming that this effect of TGF- $\beta 2$ is dependent on the upregulation of fibronectin.

FAK is the downstream effector of the TGF- $\beta 2 / f i b r o n e c t i n$ axis. FAK is required for the signaling cascade initiated by the interaction between integrins and ECM proteins, which also promotes cell migration (21). To investigate whether FAK was the downstream effector of the TGF- $\beta 2 /$ fibronectin axis, HLE-B3 cells were first treated with different doses $(0,0.1,0.5$, 1,5 and $10 \mathrm{ng} / \mathrm{ml}$ ) of TGF- $\beta 2$ and FAK activity was analyzed by western blot analysis. TGF- $\beta 2$ dose-dependently activated FAK, as reflected by the phosphorylation of FAK at Y397 after $48 \mathrm{~h}$ of treatment (Fig. 3A and B). Notably, the activation of FAK by TGF- $\beta 2$ was a delayed event, as the increase in FAK phosphorylation was not detected before $24 \mathrm{~h}$ of treatment (data not shown). To assess whether FAK activity is required for the pro-migration effect of TGF- $\beta 2$, FAK activity was blocked using the FAK inhibitor, 1,2,4,5-tetraaminobenzene tetrahydrochloride. Treatment with FAK inhibitor at a non-toxic dose 

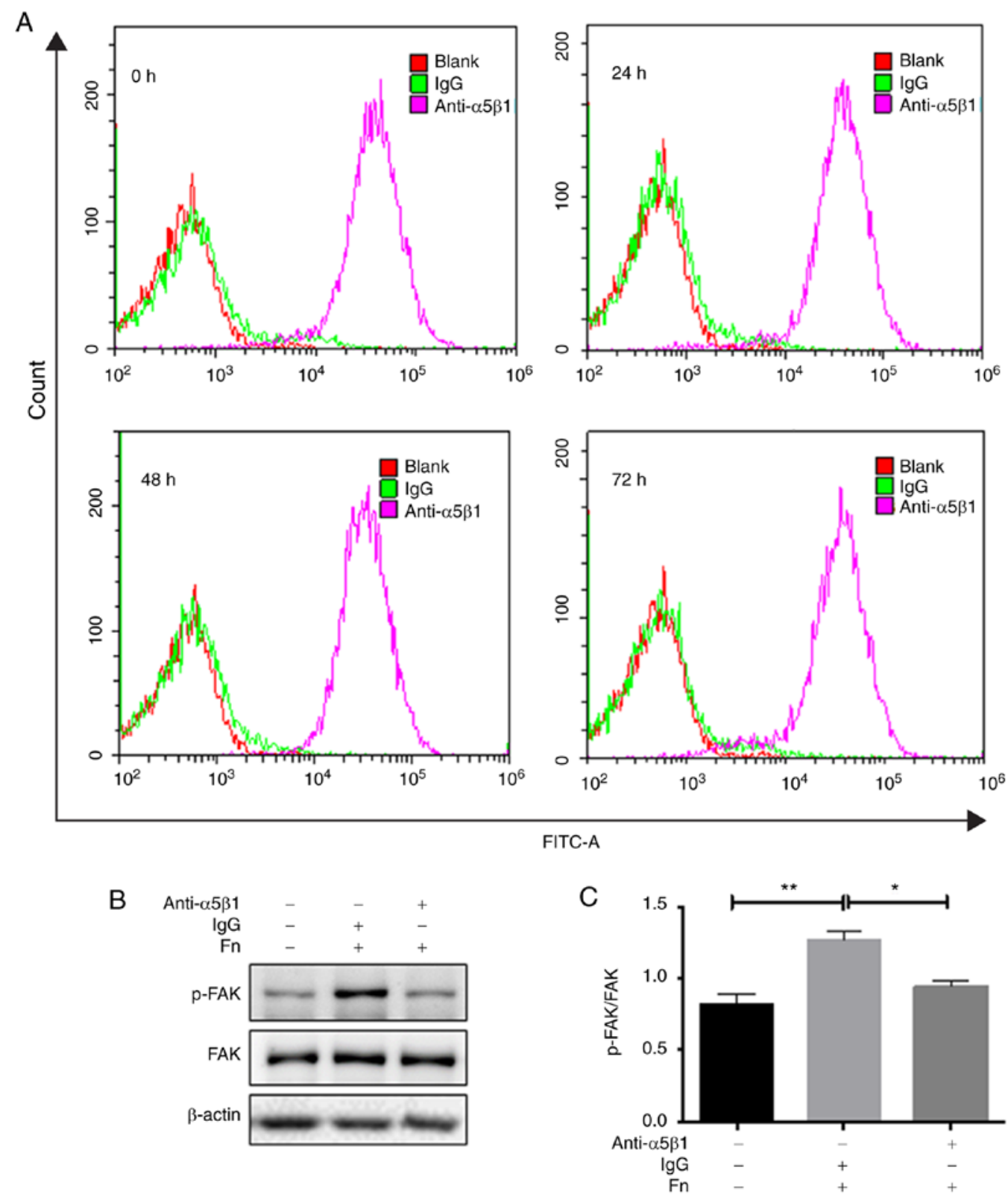

Figure 4. Integrin $\alpha 5 \beta 1$ mediates FAK activation by Fn in HLE-B3 cells. HLE-B3 cells were treated with transforming growth factor- $\beta 2$ (10 ng/ml) for various time intervals $(0,24,48$ and $72 \mathrm{~h})$ and stained with $\alpha 5 \beta 1$ integrin antibody (1:100). (A) Flow cytometry was performed. HLE-B3 were pretreated with anti- $\alpha 5 \beta 1$ integrin antibody (1:100) for $1 \mathrm{~h}$ and then seeded on a culture surface coated with fibronectin $(50 \mu \mathrm{g} / \mathrm{ml})$ or polylysine for $1 \mathrm{~h}$. (B) Western blot analysis was performed to examine levels of p-FAK. (C) Quantification of western blot analysis results. A one-way analysis of variance followed by a Least Significant Difference post-hoc-test was used to assess mean differences from multiple groups. Data are presented as means \pm standard error of the mean. ${ }^{*} \mathrm{P}<0.05$ and ${ }^{* *} \mathrm{P}<0.01$. FAK, focal adhesion kinase; HLE, human lens epithelial cells; $\mathrm{p}$, phosphorylated; FITC-A, fluorescein isothiocyanate A; Fn, fibronectin.

(1-2 $\mu \mathrm{M})$ efficiently inhibited FAK Y397 phosphorylation and, notably, decreased the migration capacity of HLE-B3 cells (Fig. 3C-E). These results indicated that FAK serves as a downstream target of TGF- $\beta 2$ to promote cell migration. As FAK signaling is activated upon the binding of ECM proteins with their cell surface binding partners, integrins, it was hypothesized that the TGF- $\beta 2$-induced expression of fibronectin may participate in the activation of FAK. Indeed, HLE-B3 cells seeded on the culture surface coated with fibronectin exhibited markedly increased levels of FAK phosphorylation compared with cells seeded on collagen- or polylysine-coated surfaces (Fig. 3F and G). Conversely, knockdown of fibronectin significantly decreased the activation of FAK by TGF- $\beta 2$ (Fig. 3H-I). Taken together, these results confirmed the presence of a TGF- $\beta 2 /$ fibronectin/FAK signaling axis in the migration regulatory network of the HLE-B3 cells.

Integrin $\alpha 5 \beta 1$ mediates FAK activation by fibronectin in HLE-B3 cells. Integrin $\alpha 5 \beta 1$ is a major binding partner and signal transducer of fibronectin in several types of cells (33). Flow cytometry was used to investigate the expression of $\alpha 5 \beta 1$-integrin in HLE-B3 cells. Integrin $\alpha 5 \beta 1$ is highly expressed on the surface of HLE-B3 cells, and treatment with TGF- $\beta 2$ for various time intervals (24-72 h) did not affect the levels of $\alpha 5 \beta 1$ integrin on the cell surface (Fig. 4A). To determine the significance of $\alpha 5 \beta 1$ integrin in fibronectin-induced phosphorylation of FAK, HLE-B3 cells were pretreated with an $\alpha 5 \beta 1$ integrin neutralizing antibody for $1 \mathrm{~h}$ prior to seeding on a culture surface coated with fibronectin. 
Table I. Anterior chamber inflammatory reaction grading following surgery.

\begin{tabular}{|c|c|c|c|c|c|c|}
\hline \multirow[b]{3}{*}{ Grades } & \multicolumn{6}{|c|}{ Treatments } \\
\hline & \multicolumn{3}{|c|}{ Dimethyl sulfoxide, $\mathrm{n}$} & \multicolumn{3}{|c|}{ Focal adhesion kinase inhibitor, $\mathrm{n}$} \\
\hline & Day 1 & Day 7 & Day 14 & Day 1 & Day 7 & Day 14 \\
\hline None & 0 & 0 & 6 & 0 & 1 & 7 \\
\hline Mild & 1 & 3 & 1 & 0 & 3 & 1 \\
\hline Moderate & 2 & 4 & 1 & 1 & 4 & 0 \\
\hline Severe & 5 & 1 & 0 & 7 & 0 & 0 \\
\hline
\end{tabular}

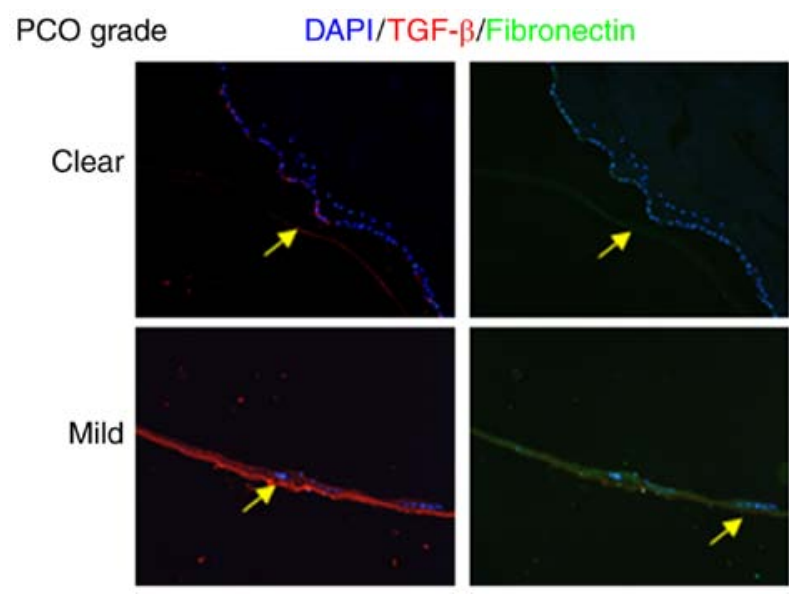

Figure 5. Immunofluorescence staining of lens capsule cryosections from non-PCO and mild PCO rabbits. Red indicates TGF- $\beta$ staining; green represents Fibronectin staining and blue staining denotes DAPI staining (original magnification, x10). Yellow arrows indicate the posterior capsules. PCO, posterior capsule opacification.

The western blot analysis results demonstrated that inactivation of $\alpha 5 \beta 1$ integrin inhibited fibronectin-induced phosphorylation of FAK at Y397 (Fig. 4B and C). Therefore, while TGF- $\beta 2$ does not affect the surface expression of $\alpha 5 \beta 1$ integrins in HLE-B3 cells, these integrins are mediators of fibronectin-dependent activation of FAK.

Inhibition of FAK activity attenuates PCO development in vivo. Considering the key role of FAK in TGF- $\beta 2$-enhanced cell migration, the present study aimed to investigate whether the inhibition of FAK activity prevented or delayed the development of PCO in a rabbit model. Cataract surgery was performed to generate PCO models. To confirm the upregulation of TGF- $\beta$ and fibronectin in the rabbit model, immunofluorescence staining was performed, and clearly demonstrated increased TGF- $\beta$ and fibronectin levels in the PCO mild group but not in the clear group (Fig. 5). Subsequent to establishing the PCO model, rabbit eyes were subconjunctivally injected with FAK inhibitor or DMSO on a daily basis, and the in vivo toxicity and the effect on PCO development were monitored. Anterior chamber inflammatory reaction grading results are summarized in Table I. The results of PCO images grading by experienced ophthalmologist are presented in Table II. Notably, DMSO-treated eyes developed PCO, as determined by opacification of the posterior capsule on day 60 , while FAK inhibitor-treated eyes exhibited markedly less severe symptoms (Fig. 6). These results suggested that inhibition of FAK activity may attenuate PCO development in vivo.

\section{Discussion}

LECs, functionally coupled to one another, regulate the majority of the homeostatic functions of the lens $(34,35)$. Following cataract surgery residual aberrant epithelial cells in injured tissues trigger a dysregulated repair process, characterized by cell migration towards the posterior capsule and ECM deposition, which results in secondary visual loss (36). TGF- $\beta 2$ is considered the most important cytokine responsible for this ectopic wound healing process (37). It was previously demonstrated that TGF- $\beta 2$ even participates in non-canonical pathways to amplify and accelerate PCO formation (38). Studies in humans and rodents demonstrate that TGF- $\beta$ levels become increased in the aqueous humor in response to trauma $(39,40)$. In addition, it was identified that short intervals of exposure of TGF- $\beta 2$ may result in long-term changes to lens epithelial cells and their underlying matrix (41). Concurrently, CAT-152 (a specific anti-TGF- $\beta 2$ human antibody) is capable of suppressing the actions of TGF- $\beta 2$. A single application of an antibody similar to this at the time of surgery may therefore confer long-term protective effects to prevent sustained TGF- $\beta 2$ actions in PCO (41). A previous study also indicated that anti-fibronectin antibodies may inhibit migration of LEC in patients (32). Combinational therapy that inhibits integrins and mitogenic growth factors appears to be promising for the prevention of PCO (42). In summary, the data from the present study indicated that, in the pathogenesis of PCO, fibronectin was an essential mediator in the crosstalk between integrins and TGF- $\beta$ signaling by the activation of FAK, and inhibition of FAK activity markedly decreased TGF- $\beta$-induced cell migration and PCO formation in vitro and in vivo.

Combinatorial signaling involving integrin and TGF receptors has been well established in fibrotic diseases and tumor metastasis (43-45); however, whether they cooperate in the development of PCO and how they communicate remains unclear. In the present study, it was demonstrated that TGF- $\beta 2$ activated FAK phosphorylation and promoted human LEC migration in a dose-dependent manner. Inhibition of FAK activity by 1,2,4,5-tetraaminobenzene tetrahydrochloride, a selective FAK inhibitor, abrogated TGF- $\beta 2$-induced cell migra- 
Table II. Posterior capsule opacification grade at day 60 following surgery.

Treatment

\begin{tabular}{lcc} 
& \multicolumn{2}{c}{ Treatment } \\
\cline { 2 - 3 } Grade & Dimethyl sulfoxide & $\begin{array}{c}\text { Focal adhesion } \\
\text { kinase inhibitor }\end{array}$ \\
\hline Clear & 0 & 0 \\
Minimal & 1 & 3 \\
Mild & 1 & 3 \\
Moderate & 2 & 2 \\
Severe & 4 & 0 \\
\hline
\end{tabular}

A
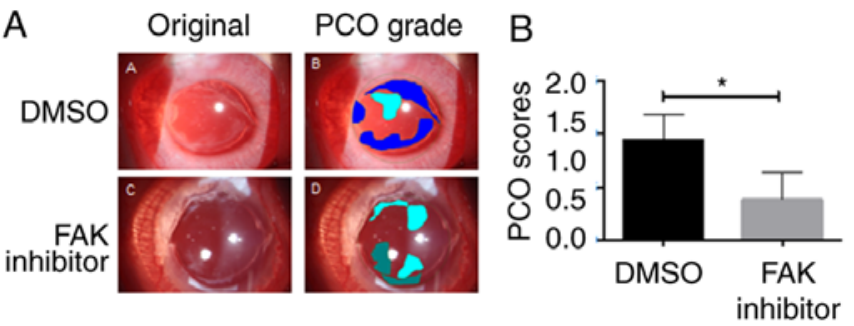

Figure 6. Inhibition of FAK activity attenuated PCO development in vivo. (A) Images of rabbit eyes treated with $10 \mu 1$ DMSO or $10 \mu 1$ 1,2,4,5-tetraaminobenzene tetrahydrochloride $(10 \mu \mathrm{M})$ at day 60 following surgery were analyzed by evaluation of posterior capsule opacification software. (B) The PCO scores from the two groups were analyzed by the Student's t-test and demonstrated a significant difference. Data are presented as means \pm standard error of the mean. ${ }^{*} \mathrm{P}<0.05$. FAK, focal adhesion kinase; $\mathrm{PCO}$, posterior capsule opacification; DMSO, dimethyl sulfoxide.

tion. This suggested that FAK signaling may be involved in TGF- $\beta 2$-mediated disorders. Notably, FAK activation occurred in a delayed and cell adhesion-dependent manner: Only when human LECs were treated with various concentrations of TGF- $\beta 2$ for $48 \mathrm{~h}$ was the phosphorylation of FAK detected and increased dose-dependently. However, fibronectin may increase the FAK activity as soon as the cells adhere. This indicates that fibronectin may serve a mediating role in the crosstalk between integrins and TGF- $\beta$ signaling. A previous study identified that secreted fibronectin assisted ovarian cancer OvCa cells in establishing an initial metastatic colony (46). Secretion and polymerization of fibronectin in the ECM is required for promoting cell migration. This may explain why the activation of FAK was relatively delayed in the present study. Downregulation of fibronectin attenuated cell migration in gastric cancer (GC) cells (47). Furthermore, in late-stage human colorectal cancer, fibronectin depletion significantly inhibited the migration of shARNT cells (48). In the present study, inhibition of fibronectin function by the RGD peptide attenuated cell adhesion and motility. Similarly, knockdown of fibronectin abolished TGF- $\beta 2$-induced FAK activation and cell migration. These results are consistent with our hypothesis that the increased synthesis of ECM proteins by TGF- $\beta 2$ stimulation may also be involved in and amplify TGF- $\beta 2$-induced dysregulation. Integrin $\alpha 5 \beta 1$ is a specific receptor for fibronectin that is highly expressed on human LECs. A previous study in human mesangial cells demonstrated that TGF- $\beta$ regulates integrins by increasing their expression level or upregulating their activity (49). In the present study, $\alpha 5 \beta 1$-integrin was not upregulated following TGF- $\beta 2$ treatment, but blocking the receptor with a neutralizing antibody significantly inhibited FAK activation by fibronectin. These results suggested that TGF- $\beta$ regulated integrin signaling by increasing the expression of its ligand, rather than the receptor itself.

Previously, FAK has been identified as a major drug target, and FAK-targeting inhibitors have entered clinical trials in a wide range of human cancer types (50). The present study provided in vitro evidence that the inhibition of FAK activity abrogated TGF- $\beta 2$-induced cell migration in a dose-dependent manner. An in vivo rabbit model also demonstrated that daily subconjunctival injection of FAK inhibitor decreased PCO formation and limited its severity. A recent study indicated that deletion of Integrin $\beta-1$ triggers stress response and cell death (51). Inhibition of FAK is likely to exert a similar effect of deletion of Integrin $\beta$-1. It may therefore by hypothesized that, compared with DMSO treated rabbit groups, LECs in FAK inhibitor (1,2,4,5-tetraaminobenzene tetra hydrochloride) treated rabbits may undergo increased apoptosis and decreased migration. More detailed studies are required to address this. In summary, the data of the present study established the central role of the TGF- $\beta 2 /$ fibronectin/integrin/FAK axis in the regulation of LEC migration, and provided novel insight into the potential application of FAK inhibitors in the prevention/treatment of PCO.

\section{Acknowledgements}

Not applicable.

\section{Funding}

The present study was supported by the National Science Foundation of China (grant no. 81470614).

\section{Availability of data and materials}

All data analyzed during this study are included in this published article.

\section{Authors' contributions}

JLiu, DX, JLi, YS and CP designed the study. JLiu, NG, CL and RJ conducted the experiments; RJ and BM contributed to set up EPCO2000 software; JLiu, RJ, BW and CL analyzed the data; and JLiu and YS wrote the manuscript.

\section{Ethics approval and consent to participate}

All animal experiments complied with the ARRIVE guidelines and the 2013 AVMA Guidelines for the Euthanasia of Animals and were approved by the Animal Experimentation Center Affiliated to the Medical School of Xi'an Jiaotong University. All authors read and approved the final manuscript.

\section{Patient consent for publication}

Not applicable. 


\section{Competing interests}

The authors declare that they have no competing interests.

\section{References}

1. Wormstone IM and Eldred JA: Experimental models for posterior capsule opacification research. Exp Eye Res 142: 2-12, 2016.

2. Nibourg LM, Gelens E, Kuijer R, Hooymans JM, van Kooten TG and Koopmans SA: Prevention of posterior capsular opacification. Exp Eye Res 136: 100-115, 2015.

3. Kane CJ, Hebda PA, Mansbridge JN and Hanawalt PC: Direct evidence for spatial and temporal regulation of transforming growth factor beta 1 expression during cutaneous wound healing. J Cell Physiol 148: 157-173, 1991.

4. Tan X, Zhu Y, Chen C, Chen X, Qin Y, Qu B, Luo L, Lin $\mathrm{H}, \mathrm{Wu} \mathrm{M}$, Chen $\mathrm{W}$ and Liu Y: Sprouty 2 suppresses epithelial-mesenchymal transition of human lens epithelial cells through blockade of Smad2 and ERK1/2 pathways. PLoS One 11: e0159275, 2016.

5. Leask A: Potential therapeutic targets for cardiac fibrosis: TGFbeta, angiotensin, endothelin, CCN2, and PDGF, partners in fibroblast activation. Circ Res 106: 1675-1680, 2010.

6 . Munger JS and Sheppard D: Cross talk among TGF- $\beta$ signaling pathways, integrins, and the extracellular matrix. Cold Spring Harb Perspect Biol 3: a005017, 2011.

7. Varadaraj A, Jenkins LM, Singh P, Chanda A, Snider J, Lee N, Amsalem-Zafran AR, Ehrlich M, Henis YI and Mythreye K: TGF- $\beta$ triggers rapid fibrillogenesis via a novel T $\beta$ RII-dependent fibronectin-trafficking mechanism. Mol Biol Cell 28: 1195-1207, 2017.

8. Scaffidi AK, Petrovic N, Moodley YP, Fogel-Petrovic M, Kroeger KM, Seeber RM, Eidne KA, Thompson PJ and Knight DA: Alpha(v)beta(3) Integrin interacts with the transforming growth factor beta (TGFbeta) type II receptor to potentiate the proliferative effects of TGFbetal in living human lung fibroblasts. J Biol Chem 279: 37726-37733, 2004.

9. Galliher AJ and Schiemann WP: Beta 3 integrin and Src facilitate transforming growth factor-beta mediated induction of epithelial-mesenchymal transition in mammary epithelial cells. Breast Cancer Res 8: R42, 2006.

10. Margadant $C$ and Sonnenberg A: Integrin-TGF-beta crosstalk in fibrosis, cancer and wound healing. EMBO Rep 11: 97-105, 2010.

11. Leask A: Focal adhesion kinase: A key mediator of transforming growth factor beta signaling in fibroblasts. Adv Wound Care (New Rochelle) 2: 247-249, 2013.

12. Thannickal VJ, Lee DY, White ES, Cui Z, Larios JM, Chacon R, Horowitz JC, Day RM and Thomas PE: Myofibroblast differentiation by transforming growth factor-betal is dependent on cell adhesion and integrin signaling via focal adhesion kinase. J Biol Chem 278: 12384-12389, 2003.

13. Wormstone IM. Posterior capsule opacification: A cell biological perspective. Exp Eye Res 74: 337-347, 2002.

14. Wormstone IM, Tamiya S, Anderson I and Duncan G: TGF-beta2-induced matrix modification and cell transdifferentiation in the human lens capsular bag. Invest Ophthalmol Vis Sci 43: 2301-2308, 2002.

15. Dawes L, Elliott R, Reddan J, Wormstone Y and Wormstone I: Oligonucleotide microarray analysis of human lens epithelial cells: TGFbeta regulated gene expression. Mol Vis 13: 1181-1197, 2007.

16. Walker $\mathbf{J}$ and Menko AS: Integrins in lens development and disease. Exp Eye Res 88: 216-225, 2009.

17. Niwa Y, Kanda H, Shikauchi Y, Saiura A, Matsubara K, Kitagawa T, Yamamoto J, Kubo T and Yoshikawa H: Methylation silencing of SOCS-3 promotes cell growth and migration by enhancing JAK/STAT and FAK signalings in human hepatocellular carcinoma. Oncogene 24: 6406-6417, 2005.

18. Choi I, Kim B, Byun JW, Baik SH, Huh YH, Kim JH, Mook-Jung I, Song WK, Shin JH, Seo H, et al: LRRK2 G2019S mutation attenuates microglial motility by inhibiting focal adhesion kinase. Nat Commun 6: 8255, 2005.

19. Hueng DY, Hsieh CH, Cheng YC, Tsai WC and Chen Y. Cordycepin inhibits migration of human glioblastoma cells by affecting lysosomal degradation and protein phosphatase activation. J Nutr Biochem 41: 109-116, 2017.
20. Payne SL, Fogelgren B, Hess AR, Seftor EA, Wiley EL, Fong SF, Csiszar K, Hendrix MJ and Kirschmann DA: Lysyl oxidase regulates breast cancer cell migration and adhesion through a hydrogen peroxide-mediated mechanism. Cancer Res 65: 11429-11436, 2005.

21. Zhao XK, Cheng Y, Cheng ML, Yu L, Mu M, Li H, Liu Y, Zhang B, Yao Y, Guo H, et al: Focal adhesion kinase regulates fibroblast migration via integrin beta-1 and plays a central role in fibrosis. Sci Rep 6: 19276, 2016.

22. Cicchini C, Laudadio I, Citarella F, Corazzari M, Steindler C, Conigliaro A, Fantoni A, Amicone L and Tripodi M: TGFbeta-induced EMT requires focal adhesion kinase (FAK) signaling. Exp Cell Res 314: 143-152, 2008

23. Cai GQ, Zheng A, Tang Q, White ES, Chou CF, Gladson CL, Olman MA and Ding Q: Downregulation of FAK-related non-kinase mediates the migratory phenotype of human fibrotic lung fibroblasts. Exp Cell Res 316: 1600-1609, 2010.

24. Wang SE, Xiang B, Zent R, Quaranta V, Pozzi A and Arteaga CL: Transforming growth factor beta induces clustering of HER 2 and integrins by activating Src-focal adhesion kinase and receptor association to the cytoskeleton. Cancer Res 69: 475-482, 2009.

25. Kilkenny C, Browne WJ, Cuthill IC, Emerson $M$ and Altman DG: Improving bioscience research reporting: The ARRIVE guidelines for reporting animal research. J Pharmacol Pharmacother 1: 94-99, 2010.

26. Knesl O, Hart BL, Fine AH, Cooper L, Patterson-Kane E, Houlihan KE and Anthony R: Veterinarians and humane endings: When is it the right time to euthanize a companion Animal? Front Vet Sci 4: 45, 2017.

27. Ma B, Yang L, Jing R, Liu J, Quan Y, Hui Q, Li J, Qin L and Pei C: Effects of Interleukin- 6 on posterior capsular opacification. Exp Eye Res 172: 94-103, 2018.

28. Camparini M, Macaluso C, Reggiani L and Maraini G: Retroillumination versus reflected-light images in the photographic assessment of posterior capsule opacification. Invest Ophthalmol Vis Sci 41: 3074-3079, 2000.

29. Raj SM, Vasavada AR, Johar SK, Vasavada VA and Vasavada VA: Post-operative capsular opacification: A review. Int J Biomed Sci 3: 237-250, 2007

30. Bainbridge P: Wound healing and the role of fibroblasts. J Wound Care 22: 407-408, 410-412, 2013.

31. Guo R,Meng Q, Guo H, XiaoL, Yang X, Cui Y andHuang Y: TGF- $\beta 2$ induces epithelial-mesenchymal transition in cultured human lens epithelial cells through activation of the PI3K/Akt/mTOR signaling pathway. Mol Med Rep 13: 1105-1110, 2016.

32. Tiwari A, Kumar R, Ram J, Sharma M and Luthra-Guptasarma M: Control of fibrotic changes through the synergistic effects of anti-fibronectin antibody and an RGDS-tagged form of the same antibody. Sci Rep 6: 30872, 2016.

33. Schaffner F, Ray AM, Dontenwill M: Integrin $\alpha 5 \beta 1$, the fibronectin receptor, as a pertinent therapeutic target in solid tumors. Cancers (Basel) 5: 27-47, 2013.

34. Rae J and Kuszak J: The electrical coupling of epithelium and fibers in the frog lens. Exp Eye Res 36: 317-326, 1983.

35. Candia OA: Electrolyte and fluid transport across corneal, conjunctival and lens epithelia. Exp Eye Res 78: 527-535, 2004.

36. Bleaken BM, Menko AS and Walker JL: Cells activated for wound repair have the potential to direct collective invasion of an epithelium. Mol Biol Cell 27: 451-465, 2016.

37. de Iongh RU, Wederell E, Lovicu F and McAvoy J: Transforming growth factor-beta-induced epithelial-mesenchymal transition in the lens: A model for cataract formation. Cells Tissues Organs 179: 43-55, 2005.

38. Meng F, Li J, Yang X, Yuan X and Tang X: Role of Smad3 signaling in the epithelial-mesenchymal transition of the lens epithelium following injury. Int J Mol Med 42: 851-860, 2018.

39. Schlötzer-Schrehardt U, Zenkel M, Küchle M, Sakai LY and Naumann GO: Role of transforming growth factor-betal and its latent form binding protein in pseudoexfoliation syndrome. Exp Eye Res 73: 765-780, 2001.

40. Ohta K, Yamagami S, Taylor AW and Streilein JW: IL-6 antagonizes TGF-beta and abolishes immune privilege in eyes with endotoxin-induced uveitis. Invest Ophthalmol Vis Sci 41: 2591-2599, 2000.

41. Wormstone IM, Anderson IK, Eldred JA, Dawes LJ and Duncan G: Short-term exposure to transforming growth factor beta induces long-term fibrotic responses. Exp Eye Res 83: 1238-1245, 2006.

42. Marcantonio J and Reddan J: TGFbeta 2 influences alpha5-beta1 integrin distribution in human lens cells. Exp Eye Res 79: 437-442, 2004 
43. Yang C, Zeisberg M, Mosterman B, Sudhakar A, Yerramalla U, Holthaus K, Xu L, Eng F, Afdhal N and Kalluri R: Liver fibrosis: Insights into migration of hepatic stellate cells in response to extracellular matrix and growth factors. Gastroenterology 124: 147-159, 2003.

44. Parvani JG, Galliher-Beckley AJ, Schiemann BJ and Schiemann WP: Targeted inactivation of $\beta 1$ integrin induces $\beta 3$ integrin switching, which drives breast cancer metastasis by TGF-3. Mol Biol Cell 24: 3449-3459, 2013.

45. Salvo E, Garasa S, Dotor J, Morales X, Peláez R, Altevogt P and Rouzaut A: Combined targeting of TGF- $\beta 1$ and integrin $\beta 3$ impairs lymph node metastasis in a mouse model of non-small-cell lung cancer. Mol Cancer 13: 112, 2014.

46. Kenny HA, Chiang CY, White EA, Schryver EM, Habis M, Romero IL, Ladanyi A, Penicka CV, George J, Matlin K, et al: Mesothelial cells promote early ovarian cancer metastasis through fibronectin secretion. J Clin Invest 124: 4614-4628, 2014.

47. Yoshino H, Enokida H, Itesako T, Tatarano S, Kinoshita T, Fuse M Kojima S, Nakagawa M and Seki N: Epithelial-mesenchymal transition-related microRNA-200s regulate molecular targets and pathways in renal cell carcinoma. J Hum Genet 58: 508-516, 2013.
48. Huang CR, Lee CT, Chang KY, Chang WC, Liu YW, Lee JC and Chen BK: Down-regulation of ARNT promotes cancer metastasis by activating the fibronectin/integrin $\beta 1 / \mathrm{FAK}$ axis. Oncotarget 6: 11530-11546, 2015.

49. Weston BS, Wahab NA and Mason RM: CTGF mediates TGF-beta-induced fibronectin matrix deposition by upregulating active alpha5beta1 integrin in human mesangial cells. J Am Soc Nephrol 14: 601-610, 2003.

50. Golubovskaya VM: Targeting FAK in human cancer: From finding to first clinical trials. Front Biosci (Landmark Ed) 19: 687-706, 2014

51. Wang Y, Terrell AM, Riggio BA, Anand D, Lachke SA and Duncan MK: $\beta 1$-integrin deletion from the lens activates cellular stress responses leading to apoptosis and fibrosis. Invest Ophthalmol Vis Sci 58: 3896-3922, 2017 